\title{
Advocacy: Are we teaching it?
}

\author{
B Gaede, ${ }^{1} \mathrm{MB}$ BCh, MMed (Fam Med), PhD; P Pillay, ${ }^{2} \mathrm{MB}$ BCh, MSc
}

${ }^{1}$ Department of Family Medicine, School of Nursing and Public Health, University of KwaZulu-Natal, Durban, South Africa

${ }^{2}$ Rural Health Advocacy Project, University of the Witwatersrand, Johannesburg, South Africa

Corresponding author: B Gaede (gaedeb@ukzn.ac.za)

\begin{abstract}
Background. Health advocacy has been identified as a key outcome competency in the undergraduate curriculum for a number of health professions by the Health Professions Council of South Africa (HPCSA) and the University of KwaZulu-Natal (UKZN), Durban, SA. Despite health advocacy and activism playing a strong role in the student body and civil society, there has been only limited engagement with the manner in which to teach health advocacy in the health professions literature.

Objectives. To assess how the faculty in health professions programmes at UKZN understood health advocacy and how it was covered in the curriculum. Methods. Focus group discussions were held with faculty from undergraduate health professions programmes at the university regarding how health advocacy was understood and how it was being integrated into the current curriculum. A thematic analysis was performed on the transcripts of the focus groups.

Results. A range of ways in which health advocacy was understood became apparent in the focus groups, with a few disciplines indicating that they do not cover health advocacy explicitly in the curriculum. Three main focus areas of health advocacy training were identified: for the profession (particularly in the smaller health professions groups); for services within the health system; and for patients or communities. The main points of departure for health advocacy were ethics and human rights and to a much lesser degree social justice. There was generally limited experience of how health advocacy could be taught as a skill and little consensus between the participating disciplines regarding the scope and content of health advocacy training. Advocacy itself was also seen as potentially risky, which could undermine the relationship between the university and the service platform. Similarly, the potential risk to whistle-blowers and the institutional culture in universities and public sector services were also seen as limitations.

Conclusions. Ample opportunities were identified for the potential teaching of health advocacy in complex professional and public sector interactions. Dual loyalty was seen to be a key dilemma for how to approach advocacy as part of work-based learning, and linked to considerable risk to the institution, educators and students. The current review offers an exciting opportunity to define more clearly what the outcome competencies of health advocacy are, particularly in the context of transformative health professions education - and how these can be operationalised in the overall curriculum.
\end{abstract}

Afr J Health Professions Educ 2019;11(2):63-67. DOI:10.7196/AJHPE.2019.v11i2.1042

Being a health advocate has been identified by the Health Professions Council of South Africa (HPCSA) as one of the outcome competencies for the undergraduate medical curriculum. ${ }^{[1]}$ This echoes similar calls throughout the world for health professionals to have a role in health advocacy. ${ }^{[2-4]}$

\section{Advocacy and activism}

It is not new to view healthcare professionals - doctors in particular - as advocates. In the late 1800s Rudolf Virchow, the father of social medicine, famously said that the physician is the 'natural advocate for the poor. ${ }^{[5]}$ In the SA context, there is also a strong tradition of healthcare practitioners being advocates and activists, such as Steve Biko and Neil Agget, who both died in custody during the apartheid regime for their stand against injustice. A number of health professions bodies and the medical school at the University of KwaZulu-Natal (UKZN) have a long history of anti-apartheid activism $^{[9]}$ and count many activists among their alumni, such as Dr Biko mentioned above. The politics of resistance to apartheid among students and faculty from many health professions programmes profoundly shaped the higher education terrain beyond universities.

In the late 1990s, the Treatment Action Campaign (TAC) started to organise itself in response to the poor handling of the HIV pandemic in southern Africa. This profoundly altered healthcare advocacy and activism, where communities and those affected by the failures of the state were at the forefront of fighting for the fulfilment of the constitutional right to healthcare provision. ${ }^{[6]}$ It has been argued that the advocacy role of TAC in response to the state's failure to provide free antiretroviral treatment to all who need it in SA, was critical in the change in policies that ultimately led to significant decreased mortality. ${ }^{[7]}$ In the process, TAC also challenged the paternalistic attitude of many healthcare professionals as the custodians of knowledge and who, with notable exceptions, were not inclined to engage in such advocacy. ${ }^{[6,8]}$

The recent groundswell of student activism demanding a critical reappraisal and decolonisation of higher education as part of the \#rhodesmustfall and \#feesmustfall movements, are reshaping the sphere of higher education. ${ }^{[11,12]}$ Therefore, advocacy per se is not a foreign concept for staff and students at universities in SA.

\section{Advocacy and health advocacy}

In health professions education there has been limited discourse regarding advocacy. ${ }^{[4]}$ The dearth of literature - locally and internationally - shows that little is being done and, with exceptions, only few institutions seem to have included advocacy as part of a transformative curricular imperative in the undergraduate curriculum. In most health professions programmes, 
much of health advocacy is subsumed in a limited way by health promotion or ethics, with references to a human rights framework or health rights. ${ }^{[4,13,14]}$ However, advocacy as a competency seems to have received much less attention. ${ }^{[4]}$

There appears to be tension regarding whether the emphasis is on health in health advocacy.

Yet, the post-apartheid discourse of higher education envisages a more engaged, appropriate graduate emerging out of higher education, who is able to transform society. It requires a move from instrumentalist education (giving skills and knowledge) to a more critical engagement with students who demonstrate agency for the improvement of patients, communities, the healthcare system - and for the country. ${ }^{[10]}$ It is an opportune moment to explore teaching advocacy as part of health advocacy - and to foreground not only the issues around privilege and inequity that are raised, but also contextualise advocacy in itself as a skill and competency in health professions education.

At UKZN, a competency framework was adopted that included health advocacy for all health professions programmes at the university. The purpose of the research, therefore, was to explore how the faculty understood advocacy in health professions education and how it was evident as an outcome competency of health advocacy (as required by the HPCSA ${ }^{[1]}$ ) for health professions education. Its objectives were to: $(i)$ describe the conceptualisation of health advocacy in health professions education at UKZN; (ii) explore how health advocacy was being taught in health professions education at UKZN; and (iii) identify opportunities for teaching health advocacy in health professions programmes at UKZN.

\section{Methods}

This exploratory study in phenomenological tradition used qualitative methods to gather data on the manner in which advocacy was understood and taught in health professions education at UKZN.

Data were gathered through focus group discussions. All faculty involved in undergraduate health professions education programmes offered at UKZN were invited to participate in the discussions to ensure broad representivity in terms of experience, professional discipline and background. The participating faculty included lecturers, module co-ordinators and programme co-ordinators from the programmes involved. Following a rigorous discussion regarding participation and anonymity, everyone who responded to the invitation to the study participated, and there were no withdrawals.

The seven focus groups were constituted around the following undergraduate professional degrees offered (listed alphabetically):

- nursing $(n=9)$

- medicine $(n=7)$

- occupational therapy $(n=7)$

- optometry $(n=3)$

- $\operatorname{pharmacy}(n=3)$

- physiotherapy $(n=5)$

- speech and language pathology $(n=3)$.

Informed consent was obtained from all participants before the focus group discussions. These discussions lasted between 33 minutes and 1 hour and 21 minutes and comprised between 3 and 9 participants. Box 1 outlines the questions that guided the discussions.
Box 1. Guide for focus group discussion

The following elements of advocacy were discussed in the focus groups:

- How would you define the concept of advocacy in health professions education?

- How do you teach health advocacy as a competency?

- What context do you teach that prepares students for gaining the competency?

- What content is taught?

- How would you ensure a critical reflection as an enabling competency?

- How would assess that students know and apply this knowledge?

- How is the content of course material validated and by whom?

- What is the value placed on advocacy as a skill by you and the university?

- Is it linked with the reputation of the university?

- What protection is afforded to those who do speak out against patient rights violations?

- Is there a license to innovate going forward?

\section{Ethical approval}

The study was part of a larger study to explore the current status of a number of competencies, as well as transformation in the curriculum, for which ethical approval was obtained from the UKZN Humanities and Social Sciences Research Ethics Committee (ref. no. HSS/0208/013). As mentioned, in the engagement with participants, considerable discussion took place regarding participation and anonymity. Based on this, we do not report on discipline-specific findings.

\section{Analysis}

The focus group discussions were audio-recorded and transcribed. An inductive analytical strategy was employed, using a pragmatic approach ${ }^{[15]}$ After re-reading and familiarisation with the material, a manual coding process was followed with codes, categories and themes that were independently identified by the 2 researchers. Through an iterative process, the themes were then compared, reordered and reviewed until consensus was reached regarding the codes, nodes and themes.

\section{Positionality of the researchers}

The focus group discussions were conducted by both authors - BG as an insider who has been active in health professions education practice and research at UKZN, and PP as an external researcher with a particular interest in health advocacy and the introduction of advocacy into the undergraduate curriculum of health professions education.

\section{Study limitations}

Because of logistical reasons, not all health professions programmes and module co-ordinators were represented as part of the data collection. The data presented therefore need to be appraised with this limitation in mind. Also, while all faculty was invited, a number of faculty with a heavy service load and who were based in remote settings, were much less likely to participate owing to service delivery pressures and distances to travel.

The study also only explored perceptions of educators and the espoused curriculum, rather than reviewing the formal curriculum, the taught curriculum or the hidden curriculum. Participation was voluntary and it 
is likely that motivated and engaged staff participated in the discussions. Furthermore, the study was cross-sectional - not longitudinal - and therefore changes or implementation of intentions over time have not been reviewed.

Our positionality introduces a desirability bias, given the focus of the study and the known interest that both researchers have in advocacy in health professions education.

\section{Results}

From the outset of the focus group discussions, participants indicated that they had a limited understanding of the concept of advocacy per se, but a broad definition of 'championing a just cause' (FG4, FG7) was central to how advocacy was seen. Health advocacy was loosely associated with health promotion and, while seen to be desirable and important, participants noted that out of the competency framework that the university had adopted, health advocacy as a field was relatively poorly described and advocacy as a competency in particular was not well understood:

'I must be honest, we have not really thought about it.' (FG1)

Participants described their approach to health advocacy largely structured around what one would advocate for - and out of the data 3 particular focus areas of advocacy emerged:

- advocacy for the profession

- advocacy for a particular service (within the health system)

- advocacy for individual patients or communities.

One participant also indicated the need to advocate for students, particularly students in need. The construct of the 3 (or 4 ) areas to focus the advocacy on was a strong node emerging from the analysis. Yet, among the professions, there was considerable variability in which the abovementioned components were identified or foregrounded:

'We are a Cinderella discipline - we are new and small and someone needs to stand up for us.' (FG3)

'[A]nd in this context we have to advocate for the expansion of [child health] services.' (FG7)

'We have no voice in the university ... '. (FG2)

Advocacy was understood as giving a voice to someone who does not have the status or capacity to speak out for themselves. The sense of being relatively small and not such a well-established profession as the larger professions further underscored the perceived need and voicelessness of being advocates for their profession. It also reflected on the privileging of medicine in the university and among health professions from focus groups other than medicine:

'We know, even if we do advocate for ourselves, we will not be listened to.' (FG5)

In this focus group in particular (FG5), the sense of not having a voice related to a sense of powerlessness within their profession and recognition by other disciplines:

'A lot of the time the students comment on their inability to advocate because they are in a position of no power.' (FG5)

'I don't think we produce a graduate who has the courage and inner power to take on advocacy.' (FG5)
Advocacy was seen to be very difficult to teach because the profession was not valued and felt undermined. In the focus group, this was contextualised within the university structures and in the broader healthcare system. It clearly influenced the way the role of a health advocate would be taught within that particular programme.

The participants pointed to their unfamiliarity and limited understanding of both the context and content in teaching advocacy and health advocacy. The context of social inequities, such as the high rate of poverty or the rural or urban differences in SA, was strongly referenced among the participants, yet broadly positioned within professional frameworks, e.g. disability, occupation, the healthcare system and human rights. The idea of social justice was implied and not central to how health advocacy was conceptualised. Between the health professions, however, there was considerable variability:

'In the community-based block, the students need to confront the issues of social justice as part of how we teach primary healthcare.' (FG5)

'There is a theory regarding access to occupation being necessary for well-being and meaning and there are concepts of justice and deprivation how the lack of occupation is understood ... and that is being taught.' (FG7)

In terms of curricular content of health advocacy, the participants viewed health promotion, ethics and rights-based approaches as covering health advocacy topics. Besides the requirements for curriculum accreditation by professional boards, there was also limited external validation of the content (e.g. by community boards, input from pressure groups or peer review). Furthermore, generally the participants were unsure regarding how advocacy as a skill could be taught. Critical reflection was a key skill that was identified in health professions education, even if its use was very limited, specifically in relation to teaching advocacy.

There were exceptions: in the undergraduate programme of a particular discipline extensive integration of advocacy and health advocacy concepts across modules and years of study was evident. While not explicitly named as an outcome competency (and therefore reflecting on curricular design), the discipline had developed both content and processes to impart skills in advocacy linked to explicit health issues. Yet, even in this profession, it was unclear how advocacy as a skill could be assessed:

'The way we work, [advocacy] has to be in everything that we teach. How can the students cope out there, if they are not prepared to take up the issues while they are at varsity?' (FG7)

'When we assess the student, the advocacy has to be there, it has to be evident in their presentation, as this is the key purpose of this module.' (FG7)

This approach was strongly contrasted to the perceived standing advocacy had within the university and that advocacy among staff and students was not linked to the institution's reputation. Despite priding itself for having prominent figures in advocacy and politics, this was not perceived as 'valued':

'Advocacy is not valued. There is some lip-service in the strategic plan, but it is clear what is important for the university. We are rewarded for research output, that's it - and not for community engagement and specifically not for advocacy.' (FG3) 
Advocacy and whistle-blowing was similarly seen as not important and, quite the opposite, being risky for students and staff. There was considerable concern regarding a sense of vulnerability when speaking out - both within the university and in the context of clinical teaching sites that were accessed on the service delivery platform. Confidentiality and possible victimisation were cited as major barriers to speaking out. Whistle-blowing and advocacy around poor services at the clinical teaching sites were seen to threaten the relationship between the university and the service platform: if a student reported abuse or poor services at a particular clinical teaching site, university faculty were concerned that the availability of the service platform would be withdrawn:

'There are certain sites that we know where there are some serious problems particularly with work ethic ... but if you are caught in between getting complaints about this site and what do you do? They can just turn around and say that they will not take any more students.' (FG7)

It points to a fragile relationship to the services platform that is currently maintained by personal relationships and goodwill:

'I think, if advocacy is important, we will need to give it a whole lot more thought. How do we teach it and what are we expecting the students to know and do at the end, how do we assess it and how do we know that it has been taught well'. (FG2)

Box 2 gives a summary of the key findings.

\section{Discussion}

The exploration of health advocacy in the curriculum of health professions education needs to be placed in the context of current discourses that shape future directions, including social accountability of medical schools, ${ }^{[16]}$ community-based education ${ }^{[17]}$ and inter-professional education and collaborative practice. In particular, the move towards transformative learning ${ }^{[10,18]}$ is critical in the manner in which health advocacy is approached and developed further in the curriculum of the health professions. The data point to both informative and formative elements in how health advocacy is currently being conceptualised. Advocacy as a competency is to a much smaller degree part of transformative health professions education. Whether

\section{Box 2. Key findings}

- Considerable variability between health professions with regard to understanding, teaching and assessing key concepts and characterisation of advocacy

- Three key themes emerged of how advocacy was understood

- for the profession

- for patients and communities

- for the health system overall

- Educators feel poorly equipped or capacitated but nevertheless request capacity development for teaching advocacy

- The university's value for social justice is not well communicated and connected to advocacy training

- Advocacy was perceived to potentially threaten the relationship between service platform and placement of students

- There was little perceived protection for those who do speak out (students and educators) the focus of transformative learning is primarily internal and a personal engagement, ${ }^{[19]}$ or social action and focused on social justice in Freire's tradition, ${ }^{[20]}$ these approaches assume a higher degree of agency than a traditional curriculum aims for. ${ }^{[21]}$

Yet, the results indicate that health advocacy is underpinned by limited theory, content and context, and, with a few exceptions, there is limited detailed understanding of advocacy as a skill. The limitations are evident in scope and depth to support the development of the healthcare professional as a change agent or global citizen, as described in the literature..$^{[21,22]}$

However, data confirm that there are ample opportunities to focus on health advocacy, which are not fully utilised. The significant amount of critical reflection and service-teaching engagements in authentic settings is already evident in the curriculum, which can create a context for possible engagement with health advocacy. In this context, it would be possible to advance health advocacy as a therapeutic tool. As an example, as a medical student is expected to expertly diagnose (as part of the therapeutic process), the student would also be expected to competently raise concerns regarding access to care to ensure that a patient is optimally treated (as part of the therapeutic process).

The participants very seldom viewed privilege and inequity as problems - the focus on the need to advocate and advance the profession outweighed engaging with the lived realities of marginalised groups. Graduating from university with a professional degree places the student in a privileged position in society, but this did not surface as a point of engagement around advocacy and the promotion of social justice. Are we providing skills and capacity to engage with this privileging in a constructive and socially accountable manner? This may be an important avenue to engage in the discourse around decolonising the curriculum, as mentioned above. ${ }^{[11]}$

A concerning finding reveals the fragile nature of the relationship building between communities, service providers and health professionals Advocating for patients was perceived to potentially threaten relationships between service platform and placement of students; consequently, a higher level of inappropriate behaviour by service staff was tolerated and not reported. It became clear that dual loyalty is one of the most difficult dilemmas. The perception that whistle-blowers are not adequately protected and that within the university and the Department of Health there was not a strong tradition of speaking out, further deepens the dilemma. Understanding the tools and legislation to use when advocating (e.g. the Public Service $\left.A c{ }^{[23]}\right)$, is the key to know how to navigate the dual loyalty Therefore, a concern arising around teaching health advocacy related to how authentic the environmental context could make any formal teaching of advocacy as a skill. If it is perceived (and the perception re-enforced by the faculty) to be difficult to speak out within the organisation, any teaching of advocacy would be perceived to be either superficial lip-service to the idea or subversive and risky.

The new HPCSA competency framework ${ }^{[1]}$ offers an opportunity to innovatively link transformative health professions education to being a health advocate that focuses on social injustice. Universities can create health professionals who are able to have an impact on the health outcomes of patients and communities and produce health advocates as change agents. It can have an additional advantage, i.e. helping to bridge the gap between disciplines if they can conceptualise a common understanding of it.

The lack of alignment of the university's reputation to advocacy for social justice is an important part of the context that needs to be considered in 
curriculum design. Accompanying research focus led by the university with an equal focus on social justice (as they are not antagonistic or mutually exclusive) would be a helpful signal to staff and students. Yet, the culture of the university cannot be divorced from those who teach and those who learn. In this context, the fear of speaking out or whistle-blowing and a sense of 'voicelessness' among the professions are of deep concern, as it shapes the hidden curriculum around agency and advocacy in profound ways. It is critical for it to be addressed in line with organisational accountability and transformation.

\section{Conclusions}

With some exceptions, being a health advocate has not been well defined in terms of skills and outcomes in the curriculum of health professions education programmes at UKZN. This review offers an exciting opportunity to define more clearly what the outcome competencies of health advocacy are, particularly in the context of transformative health professions education, and how these can be operationalised in the overall curriculum. This would align the university in a profound way with its mission of relevance and social accountability.

\section{Declaration. None.}

Acknowledgements. The authors would like to acknowledge Prof. Sabiha Essack for her leadership in the overall competencies project and the Rural Health Advocacy Project for their support and focus on health advocacy in particular. Author contributions. BG and PP jointly participated in collection and analysis of data, and drafting and finalising the manuscript.

Funding. The research was in part financially supported by the Rural Health Advocacy Project.

Conflicts of interest. None.
1. Health Professions Council of South Africa. Core Competencies for Undergraduate Students in Clinica Associate, Dentistry and Medical Teaching and Learning Programmes in South Africa. Pretoria: HPCSA, 2014 2. Royal College of Physicians and Surgeons of Canada. CanMEDS Physician Competency Framework. 2005. http://www.ub.edu/medicina_unitateducaciomedica/documentos/CanMeds.pdf (accessed 7 May 2019).

3. Gruen R. Evidence-based advocacy: The public roles of health care professionals. Med J Austr 2008;188(12):684685. https://doi.org/10.5694/j.1326-5377.2008.tb01843.x

4. Mu L, Shroff F, Dharamsi S. Inspiring health advocacy in family medicine: A qualitative study. Educ Health 2011;24(1):534.

5. Anderson M. What is social medicine? Social Med Portal 2008. http://www.socialmedicine.org/2008/03/23/ about/what-is-social-medicine/ (accessed 12 March 2019).

6. Hassim A, Heywood M, Berger N, eds. Health and Democracy: A Guide to Human Rights, Health Law and Policy in Post-apartheid South Africa. Cape Town: Siber Ink, 2008

7. Nunn A, Dickman S, Natrass N, Cornwall A, Gruskin S. The impacts of AIDS movements on the policy responses to HIV/AIDS in Brazil and South Africa: A comparative analysis. Glob Publ Health 2012;7(10):1031-1044 https://doi.org/10.1080/17441692.2012.736681

8. Rural Health Advocacy Project. Voice - a health care provider's guide to reporting healthcare challenges: Principles, tools and strategies. 2014. http://www.rhap.org.za/voice-project-manual/ (accessed 12 March 2019). 9. Noble V. A School of Struggle: Durban's Medical School and the Education of Black Doctors in South Africa. Durban: University of KwaZulu-Natal Press, 2013

10. Waghid Y. The public role of the university reconsidered. Perspect Educ 2008;26(1):19-24.

11. Pillay M, Kathard H. Decolonizing health professionals' education: Audiology and speech therapy in South Africa. Afr J Rhet 2015;7(1):193-227.

12. Jansen J. As by Fire - the End of the South African University. Tafelberg: Cape Town, 2017

13. Mann JM, Gostin L, Gruskin S, Brennan T, Lazzarini Z, Fineberg HV. Health and human rights. Health Hum Right 1994;1(1):6-23.

14. London L. What is a human rights-based approach to health and does it matter? Health Hum Rights 2008;10(1):65-80. https://doi.org/10.2307/20460088

15. Saldana J. The Coding Manual for Qualitative Researchers. Los Angeles: Sage, 2015.

16. Woolard RF. Caring for a common future: Medical schools' social accountability. Med Educ 2006;40(4):301-313 https://doi.org/10.1111/j.1365-2929.2006.02416.x

17. Worley P. Integrity: The key to quality in community-based medical education? Educ Health 2002;15(2):129-138. Worley P. Integrity: The key to quality in com
https://doi.org/10.1080/13576280210133053

18. Frenk J, Chen L, Bhutta ZA, et al. Health professionals for a new century: Transforming education to strengthen health systems in an interdependent world. Lancet 2010;376:1923-1958. https://doi.org/10.1016/S0140 6736(10)61854-5

19. Mezirow J. Transformative learning: Theory and practice. New Direct Adult Contin Educ 1997;74:5-12. https:// doi.org/10.1002/ace.7401

20. Freire P. Pedagogy of the Oppressed. New York: Continuum, 1996.

21. Hanson L. Global citizenship, global health and the internationalization of curriculum: A study of transformative potential. J Stud Int Educ 2010;14(1):70-88. https://doi.org/10.1177\%2F1028315308323207

22. Freudenberg N. Public health advocacy to change corporate practices: Implication for health education practice and research. Health Educ Behav 2005;32(3):298-319. https://doi.org/10.1177\%2F1090198105275044

23. Republic of South Africa. The Public Service Act No. 103 of 1994. 